www.jmscr.igmpublication.org

Impact Factor (SJIF): 6.379

Index Copernicus Value: 71.58

ISSN (e)-2347-176x ISSN (p) 2455-0450

crossref DOI: https://dx.doi.org/10.18535/jmscr/v6i4.208

Journal Of Medical Science And Clinical Research

IGM Publication

An Official Publication of IGM Publication

\title{
Complication of Elastic Intra-Medullary Nailing for long Bone Fracture Fixation in Paediatric Age Group
}

\author{
Authors \\ Dubey P. ${ }^{1}$, Lunawat S.K. ${ }^{2}$ \\ ${ }^{1}$ Resident Orthopedics MGM Medical College Indore, MP, India \\ ${ }^{2}$ Professor Orthopedics MGM Medical College Indore, MP, India
}

\begin{abstract}
Background: Paediatric long bone fractures are very common and most of them can be treated by nonoperative methods. Operative stabilisation only requires when either reduction or stabilisation of fracture fails with conservative methods. The old methods of operative stabilisation were having various complications. New method of fixation with titanium elastic nailing is associated with less complication.

Method: This study was to asses outcome of displaced long bone fracture treated with TENS in paediatric (5 to 12 year) age group. We have studied 30 children of diaphysial long bone fractures, treated with closed reduction and TENS with an average follow up of 1 year.

Result: In our study all fractures united complications seen in 5 patients (transient limb length discrepancy in 2 patients, pain at insertion site in 3 patient).

Conclusion: TENS is a safer method of pediatric long bone fixation but associated fewer minor complications.
\end{abstract}

\section{Introduction}

Incidence of Paediatric long bone fractures is increasing because of raised RTA and increase participation in sports. Treatment method depends on various factors like age, bone, site, displacement/angulation, compounding etc. majority of fracture are treatable with conservative methods in small children because high potential of remodelling, but fracture shaft of femur and other long bone fractures in older children, with excessive deformity like overriding, angulations and malrotation require treatment method to be re-considered. 7 Older children have decrease potential of remodelling as well as, they have tendency of loss of reduction, malunion, and joint stiffness, when treated with non operative methods. In these situations operative interventions such as external fixation, compression plating, rigid nailing and elastic nailing are required. These procedures are associated with their own complications like pin tract infection, openreduction, infection secondary procedure of implant removal, physeal injury with growth arrestetc. In children th ideal fixation is that whichgives stable reduction till hard callusformation, and should not endanger the growth plate or its blood supply. With 'Titanium Elastic Nailing' (TENS) is excellent implant for achieving these goals. It gives stable reduction and allow earlyjoint mobilisation, so as to prevent joint stiffness and also does not affect the physis. In this study we will consider the 
technique of doing tens nailing and discuss complications.

\section{Materials \& Methods}

We have prospective study of 30 children with long bone diaphyseal fractures, conducted at in the department of orthopaedics, MGM medical college Indore from July 2011 to January 2014. In our study children of age between 5-12 years with diaphyseal fractures of long bone matching the inclusion and the exclusion criteria (as given below), are subject of study. The radiographs were being taken at defined interval and patients were evaluated clinically for ROM, deformity, shortening, fracture union and hard ware related complications.

\section{Inclusion Criteria}

1. 5-12 years of age,

2. Diaphyseal fractures and Metaphyseal fractures of femur,

3. Closed or Gustilo-Anderson type 1 open fractures only.

\section{Exclusion Criteria}

1) Grossly comminuted or multi fragmentary fractures,

2) Gustilo-Anderson type 2 or more open fractures,

3) Pathological fracture

\section{Principle and Technique}

The working principal of TENS is three point fixation. It constitute of symmetrical elastic construct formed by 2 nails which counteracts the various deforming forces acting on fracture site.6, 9 Fracture of long bone requires 2 nails for each bone except for radius- ulna in which we use one nail for each bone. The end of nail is tapered, bevelled and curved, which make insertion of nail from entry point and negotiation through fracture easier. The nails size available is $2 \mathrm{~mm}$ to $4 \mathrm{~mm}$ with difference of $0.5 \mathrm{~mm}$ and are colour coded according to size. For three point fixation principal diameter of nail should be $40 \%$ of canal diameter at isthmus, while in in radius-ulna in which we use single nail per it is $60 \%$ of canal diameter. ${ }^{[6,8]}$ to increase stability pre-bending of the nail requires before insertion. After bending the nail make curvature of nail should be 3 times the canal diameter. ${ }^{[6,8]}$ (fig 1 )

The apex of curvature of nail should lie over fracture site. The entry should be made away from physis. To spare the physis6

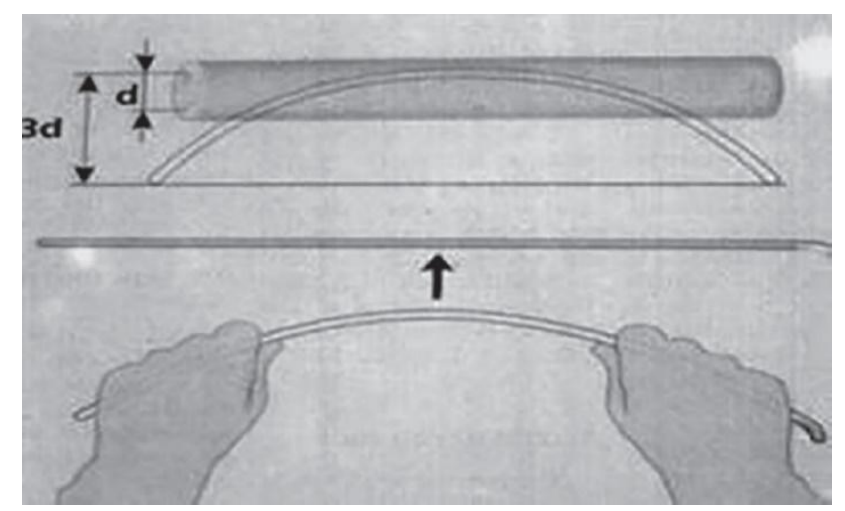

Fig. 1 Pre-bending of nail

Entry points for different bones are as follow 6 Fracture shaft femur- we do retrograde nailing, with entry $2.5 \mathrm{~cm}$ proximal to physis.

2nails of same size, one from medial side and one rom lateral side, were used. (Fig. 2)

Fracture tibia-antegrade or retrograde nailing with entry point just $2 \mathrm{~cm}$ away from physis, one from medial side and one from lateral side (Fig.3)

Fracture humerus- we have done antegrade nailing with entry point just distal to physis from lateral aspect. Entry points of both nails were on lateral side, but one nail precountered in C-shaped while another in S-shape to engage opposite cortex at lower end. (Fig. 4)

Fracture radius - retrograde nailing with entry point just lateral to Lister tubercle. (Fig. 5)

Fracture ulna-antegrade nailing with entry point just distal to physis (Fig. 6) 


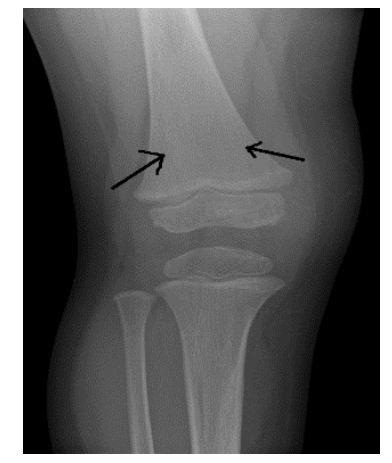

Fig 2

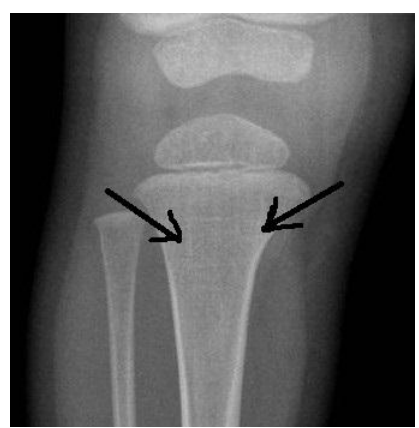

Fig 3

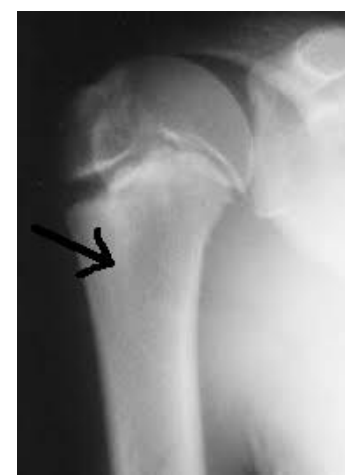

Fig. 4

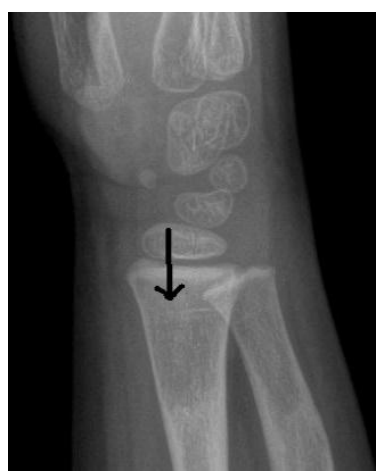

Fig. 5

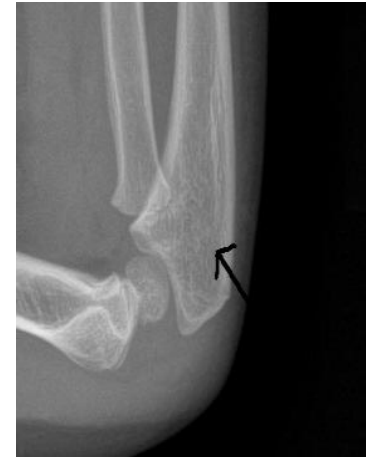

Fig. 6
Statistics- We have studied 30 children, in which 19 were male and 11 were female children of 5 to 12 yrs of age. This include 19 fractures of shaft femur, 2 of fracture shaft humerus, 6 of fracture radius unla and 3 patients having fracture tibia including one patient fracture femur and tibia in same limb. One patient with fracture tibia was associated with vascular compromised due to fracture fragment compressing vessel. Diaphyseal fractures of all long bones with sub- trochant rich fracture of femur included in this study. Pattern of fractures in this study were transverse, oblique, spiral or fracture with small wedge with other cortex in continuity. 2 fractures of shaft of femur and one fracture of tibia were compound with Gustilo-Enderson type 1 grade. All patients operated under spinal or general anaesthesia form 1st to 7th day after trauma. All patients treated with closed reduction and TEN fixation. They were followed minimally up to 1year and outcome was assessed on the basis of Flynn criteria

\section{Results}

Fracture shaft of femur- Union time for fracture ranges from 6 weeks to 12 weeks. Partial Weight bear in started at an average 3 weeks. Full weight bearing started between 6 weeks to 10 weeks. Range of motion was normal in all except in one patient with fracture femur and tibia in ipsilateral site, has decreased range of motion of knee. Pain at entry site seen in 2 patient, which was associated protruding nail from entry site (Fig 7). Transient limb length inequality of more than $1 \mathrm{~cm}$ was seen in 2 patients.

Fracture radius-ulna- Fracture united between 68 weeks in all 5 patients. None of patients was having infection. Range of motion was normal in all patients.

Fracture humerus- Fracture united at 8 weeks in a patient without infection and Pain at entry site. Range of motion was normal in all direction.

Fracture tibia- One patient was having associated injury with fracture shaft femur while another patient was having vascular compromise with fracture fragment compressing the artery. Post operative flow became normal immediately. Fracture united between 6-8 weeks in both patient. 
No one have infection and Pain at entry site was in one patient.

The result was excellent in $84 \%$, satisfactory in $6 \%$ cases and poor in $10 \%$ cases according to Flynn Criteria (Table 1)

In 2 patients, satisfactory result was due to transient limb length discrepancy which is due to growth potential in children which decreased with time, while in 3 patient result was poor because of pain at entry site due to protruding nail at entry site (Fig. 7). It can be prevented with correct technique and proper instrumentation.

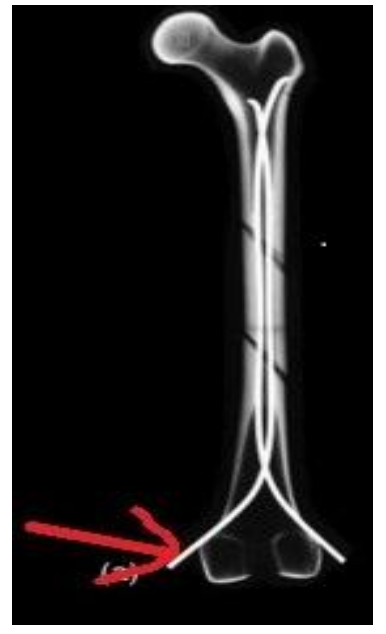

Fig. 7

Table 1

\begin{tabular}{|l|c|c|c|c|c|c|c|}
\hline & \multicolumn{3}{|c|}{ Result } & \multicolumn{3}{c|}{ Complication } \\
\hline $\begin{array}{l}\text { Titanium } \\
\text { elastic nail }\end{array}$ & $\begin{array}{c}\text { No. of } \\
\text { patient }\end{array}$ & excecellent & satisfactory & poor & $\begin{array}{c}\text { Pain at nail entry } \\
\text { site }\end{array}$ & malalignment & leanthening \\
\hline FEMUR & 19 & 15 & 2 & 2 & 2 & 0 & 2 \\
\hline RADIUS-UNLA & 6 & 6 & 0 & 0 & & 0 & 0 \\
\hline TIBIA & 3 & 2 & 0 & 1 & 1 & 0 & 0 \\
\hline HUMERUS & 2 & 2 & 0 & 0 & 0 & 0 & 0 \\
\hline
\end{tabular}

\section{Discussion}

Long bone fractures are very common, In Paediatric age (5-12 years) which can be treated most of the time with conservative methods. But when it does not work operative methods require such as external fixation, open reduction and plate fixation, locked nails etc.

External fixation has common complication of pin track infection and also associated with on unionandre-fracture ${ }^{[1,2]}$ It is also inconvenient for patients. Plating requires open reduction which is associated with infection and blood loss, further implant removal is a major surgery after fracture union. ${ }^{[3]}$

Locked nails cannot be used in children because of growing physis and associated with avascular necrosis. ${ }^{[4,5]}$ These all complication can be overcome by TENS. It does not require open reduction, no physeal injury and very low risk of infection and also the blood loss is minimal and the implant removal is easier procedure.

Femoral fracture- In femur we have used 2 prebend nails, having opposite action, so it prevent side to side and antero-posterior translation of fracture, angulations, axial compression and rotation at fracture site. ${ }^{[6,9]}$ As the rotational stability is minimal, we use to apply de-rotation bar for three weeks to add rotational stability in patients of 8-12 year of age. As the fixation is stable knee bending started immediately, partial weight bearing started at 3 weeks and full weight bearing started when the sign of union seen on X-rays. Implant removal planned when fracture consolidated, at least after 6 month. The implant removal is easy procedure, with small nick, end of nail can be pulled out with nose plaier.

Radius- ulna fracture- Procedure was same as for femur but one nail used for each bone with diameter of nail to be $60 \%$ of canal diameter Retrograde nailing for radius and ante-grade nailing in ulna was done in 6 cases Fracture humerus. We have done only 2 case of fracture humerus because with conservative management most of fractures are reduced within acceptable ranges, ${ }^{[7]}$ further the criteria of acceptable reduction is wider in humerus. In our case we were fail to achieve acceptable reduction by 
conservative method so, antegrade nailing done with 2 nails, one in ' $\mathrm{C}$ ' shape while another in ' $\mathrm{S}$ ' shape.

Fracture tibia- Operative treatment is rarely required in a closed tibial fracture in children, ( $<5 \%$ of cases). In our study one patient was associated with vascular compromise and another was associated with fracture shaft femur and third patient was having grossly displaced fracture with overweight patient. All three cases treated with closed reduction and 2 nails used for antegrade nailing. Vascular flow become normal in that patients.

\section{Conclusion}

Intramedullary elastic nailing for paediatric long bone fracture is easy procedure with excellent results some cases have poor results due protruding nail which should be taken care of with proper technique

\section{References}

1. Aronson J, Tursky EA external fixation of femur in children peditrorthop 12: 157163, 1992

2. Kirshenbaum P, Albert MC, Robeston WW, et al : complex femur fractures in children: Treatment with external fixation. J PediatrOrthop 10 : 588-591, 1990

3. Ward WT, Levy J, Kaye A Compression plating for child and adolescent fractures Peditr Orthop 626-532 1992

4. Galpin RD, Willis RB, Sahoon $\mathrm{N}$ :Intemedullary nailing Of peadiatric orthop14: 184-189, 1994

5. Beaty JH, Austin SM, Warner WC, et al : Interlocking intramedullary nailing of femoral shaft fractures in adolescents : Preliminary results and complication. J pediatrOrthop 14 : 178-183 1994

6. Dietz HG et al Synthes: Titanium Elastic Nail(TEN) Surgical technique. Mathys Medical Ltd. Osteosynthesis
7. Caviglia H, Garrido CP, Palazzi FF, et al: Pediatric fractures of the humerus. Clin Orthop Relat Res 2005; 432:49.

8. Stephen D Heinrich: the operative stabilisation of Pediatric diaphyseal femur fractures with flexible intramedullary nails. Operative techniques in orthopaedicccsvol 5, no. 2 (April), $1995=115-125$

9. A. Abosala, D. J. Westacott, J. L. Cunningham: A Biomechanical Study of the Stability of Titanium Elastic Nails in the Treatment of Oblique Segmental Fracture of the Femur in Children. The Internet Journal of Orthopedic Surgery. 2011 Volume 19 Number 1. DOI: 10. $5580 / 2169$ 